\title{
Improvement of aggregate- associated organic carbon and its stability in bauxite residue by substrate amendment addition
}

by Tian, T., Liu, Z., Zhu, F., Hartley, W., Ye, Y. and Xue, S.

Copyright, publisher and additional information: this is the author accepted manuscript. The final published version (version of record) is available online via Wiley. This article may be used for non-commercial purposes in accordance with Wiley Terms and Conditions for Self-Archiving.

Please refer to any applicable terms of use of the publisher.

DOI: https://doi.org/10.1002//dr.3609

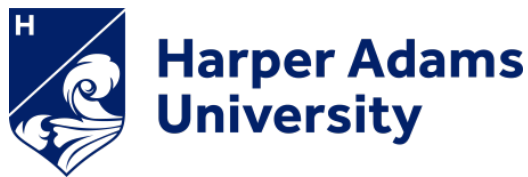




\title{
Improvement of aggregate-associated organic carbon and its stability
}

\section{in bauxite residue by substrate amendment addition}

\author{
Tao Tian ${ }^{1}$, Zheng Liu ${ }^{1}$, Feng Zhu*, William Hartley ${ }^{2}$, Yuzhen Ye $^{1}$, Shengguo Xue ${ }^{1 *}$ \\ ${ }^{1}$ School of Metallurgy and Environment, Central South University, Changsha 410083, China \\ ${ }^{2}$ Crop and Environment Sciences Department, Harper Adams University, Newport, Shropshire, TF10 8NB, United Kingdom
}

\begin{abstract}
Buxite residue is a highly alkaline byproduct, routinely discarded at residue disposal areas. Soil formation at these disposal sites is necessary in order to encourage revegetation and prevent residue losses to the wider environment. Addition of organic amendments may therefore serve as an effective tool to accelerate soil formation. The current study aimed to investigate the effect of different amendments on aggregate stability and the distribution of organic and humic substances in bauxite residue. A column experiment was used to investigate aggregate distribution, stability, and aggregate-associated $\mathrm{C}$ using phosphogypsum and vermicompost (PVC), and biosolids and microorganisms (BSM). Results demonstrated that amendment additions increased macro-aggregate formation whilst also enhancing aggregate stability. From statistical histograms, mean particle sizes of CK, PVC, and BSM treatments were observed to be $\sim 114, \sim 157$, and $\sim 188 \mathrm{~nm}$, respectively. Compared with CK treatments, the increased contents of organic carbon, humic acid, and fulvic acid reached 1.65, 1.59, and 1.57 for PVC treatmetns, and 2.90, 2.69, and 2.60 for those with BSM. Furthermore, enhancement of aggregate stability involves an increase in organic carbon in residue aggregates, resulting in more organic carbon accumulating in larger aggregates. BSM treatments revealed significant improvement in carbon sequestration. This is mainly due to organic macromolecules, such as cellulose and hemicellulose, being broken down into polysaccharides, proteins, and humic substances through increasing microbial activity. The findings provide evidence that treatment with BSM shows potential for soil formation and vegetation establishment of bauxite residue.
\end{abstract}

KEYWORDS: substrate amendment; bauxite residue; aggregate distribution; aggregate stability; organic carbon; carbon sequestration

* E-mail: sgxue@csu.edu.cn; zhufeng1990@csu.edu.cn 


\section{1। INTRODUCTION}

Bauxite residue, generated as part of the alumina production process, is an alkaline solid waste (Kong et al., 2018). Large volumes of bauxite residue, contained within disposal areas, may result in environmental issues including land occupation, contamination of underground water supplies, and air pollution from surface dust (Courtney et al., 2013; Oral et al., 2019). Sustainable development of the alumina industry therefore faces increasing challenges due to these environmental risks (Burke et al., 2012). Formation of soil at the disposal areas is therefore one of the most effective approaches to achieve large-scale ecological improvements (Courtney et al., 2013; Xue et al., 2019b). Consequently, improvements in aggregate structure and organic carbon content are essential to reduce environmental risks (Goloran et al., 2017; Zhu et al., 2018; Tian et al., 2019a). Transforming residue into a soil-like medium for plant establishment nevertheless requires a series of physical, chemical and biological processes (Xue et al. 2019b), and so optimization of its physical structure, and improvement in organic nutritional components, is necessary for the process of soil formation.

Aggregates play a key role in the formation of soil structure by protecting and stabilizing organic carbon (Yousefi et al., 2008; Yilmaze and Sönmez, 2017; Rabot et al., 2018). Initially, formation of aggregates usually occurs by silt and clay bonding together into microaggregates, from binding agents such as humic materials and complexes of polyvalent cations. Microaggregates then bind together to form macroaggregates by association with fungal hyphae, fine roots, and plant- and microbial-derived polysaccharides (Six et al., 2004). Soil organic carbon is one of the main cementing agents in the formation of stable aggregates, which is beneficial to preservation of soil fertility, improvement of crop yield, and enhancement of carbon sequestration (Chaplot and Cooper, 2015). Humic substances, considered recalcitrant, may act as persistent binding agents forming at the micro-aggregate level (Lugato et al., 2010). Aggregate formation associated with humic substances is usually related to carbon sequestration in soil (Bongiovanni and Lobartini, 2006). However, aggregates and humic substances in bauxite residue are usually neglected, although it has important effects on structural evolution and aggregate formation of bauxite 
residue.

Organic amendments increase organic carbon and aggregate stability in soil, which is attributed to increased microbial activity (Senesi et al., 2007; Ferro et al., 2012; Wang et al., 2014). As reported in previous studies (Aksakal et al., 2016), vermicompost can increase soil organic carbon and promote aggregate formation. In addition, vermicompost has high microbial activity which increases binding agents (Aksakal et al., 2016). Soil microorganisms, especially fungi, may play an important role in the formation and stabilization of macro-aggregates, because the hyphae produce extracellular polysaccharides that bind microaggregates into macroaggregates (Tisdall, 1994). Several studies have demonstrated that organic amendments significantly improved organic carbon and aggregate stability in saline soil (Cong et al., 2017) and barren sandy soil (Dai et al., 2019). Nevertheless, few studies have investigated the effect of organic amendments on aggregate stability and aggregate-associated humic substances in bauxite residue.

The aim of the present study was to 1) to investigate the effect of combined amendments on aggregate distribution and its stability; 2) to reveal variations in aggregate-associated organic carbon and the composition of humic substances; 3) to explore the correlation between aggregate stability and aggregate-associated carbon contents in bauxite residue.

\section{2 | MATERIALS AND METHODS}

\section{1 | Experimental design and sampling}

Bauxite residue was generated by the Bayer process and residue samples were collected from a bauxite residue disposal area in Guangxi province of China (23⒌ $\left.627^{\prime \prime} \mathrm{N}, 108^{\circ} 18^{\prime} 200 " \mathrm{E}\right)$. The residue in this work was a recently deposited sample which had been stacked for approximately two months from its production to sample collection. After being air-dried, the bauxite residue samples were passed through 2 $\mathrm{mm}$ mesh sieves. Ameliorants including phosphogypsum, vermicompost, and biosolids are described in more detail in previous studies (Tian, et al., 2019a; Tian, et al., 2019b); basic properties are presented in Table 1.

The experiment was conducted in columns as shown in Figure 1. The surface layer $(0-25 \mathrm{~cm})$ contained a mixture of bauxite residue and amendments, with the second $(25-45 \mathrm{~cm})$ and the third layers $(45-65 \mathrm{~cm})$ filled with bauxite residue. Three treatments were set up as follows: (i) CK: untreated bauxite residue; (ii) PVC: 
addition of phosphogypsum (2\% w/w) and vermicompost (4\% w/w); (iii) BSM: addition of biosolids (15\% w/w, containing $10 \%$ bagasse and $5 \%$ bran) and microbial liquid (100 mL, once every five days). The ameliorants were mixed with bauxite residue homogeneously. All treatments were performed in triplicate.

The column experiment was maintained using tap water $(175 \mathrm{~mL}$, according to local rainfall) from May 15 to June 15, 2018. Samples were collected from three different layers $(0-25 \mathrm{~cm}, 25-45 \mathrm{~cm}$, and 45-65 cm). A subsample was used for bauxite residue aggregate separation, and the remainder was sieved to $0.149 \mathrm{~mm}$ for organic carbon analysis.

\section{2 | Analysis of bauxite residue samples}

Air-dried residue samples were dry sieved using a series of sieves $(2,1,0.25$, and 0.05 $\mathrm{mm}$ ), and the fractions in each sieve were used to calculate mean weight diameter (MWD) (Tian et al., 2019a). The composition of humic substances was analyzed according to the method described by Lu (2000) and Zhang et al. (2011). Bauxite residue samples were extracted using $\mathrm{Na}_{4} \mathrm{P}_{2} \mathrm{O}_{4}+\mathrm{NaOH}$, $(0.1 \mathrm{~mol} / \mathrm{L})$ for $60 \mathrm{~min}$. The alkaline supernatant solution was then acidified to $\mathrm{pH} 3$ with $0.5 \mathrm{~mol} / \mathrm{L} \mathrm{H}_{2} \mathrm{SO}_{4}$ to separate acid-insoluble humic acid carbon (HA) and acid-soluble fulvic acid carbon (FA). For insoluble $\mathrm{HA}, 0.025 \mathrm{~mol} / \mathrm{L} \mathrm{H}_{2} \mathrm{SO}_{4}$ and $0.05 \mathrm{~mol} / \mathrm{L} \mathrm{NaOH}$ were applied to remove attached FA. Organic carbon contents of HA were determined using the $\mathrm{K}_{2} \mathrm{Cr}_{2} \mathrm{O}_{7}$ oxidation method, whilst FA was calculated by the difference between HA and the humic fraction carbon. $\mathrm{pH}$ and electrical conductivity (EC) were determined in water extracts (solid: water ratio of 1:5) (Liang et al., 2017). Organic carbon content was determined calorimetrically by oxidation with potassium dichromate (Liu et al., 2019; Tian et al., 2019b). For microstructure and surface morphology observations, air-dried samples were directly viewed by field-emission scanning electron microscopy (SEM, JSM-6330F). Surface-associated mapping was also recorded. Energy dispersive X-ray spectrophotometer (EDS) was used to inspect elemental distribution and concentrations. Structure of functional groups of organic carbon was analyzed by Fourier-transformation infrared spectra (FTIR). Collection of spectra ranged between 500 and $4000 \mathrm{~cm}^{-1}$, along with a resolution of $4 \mathrm{~cm}^{-1}$. 


\section{3 | Aggregates stability}

To obtain the mass percentage composition of aggregates for different particle sizes, the following formula was used:

$$
\mathrm{w} i=\mathrm{W} w i / \mathrm{W} \times 100 \%
$$

where $\mathrm{w}_{\mathrm{i}}$ denotes the mass percentage composition of aggregates $(\%), \mathrm{Ww}_{\mathrm{i}}$ denotes aggregate mass $(\mathrm{g})$, and $\mathrm{W}$ denotes the total mass of bauxite residue samples $(\mathrm{g})$.

Mean weight diameter (MWD) representing aggregates stability, was calculated as:

$$
\mathrm{MWD}=\sum_{i=1}^{n} \overline{X i} \times W i
$$

where $\mathrm{X}_{i}$ is the mean diameter of each size fraction and $\mathrm{W}_{i}$ is the proportion of the total sample weight corresponding to size fraction.

\section{4 | Humic carbon}

HA/FA ratio is used to evaluate the quality of humic carbon in bauxite residue. The higher ratio, obtaining larger humic acid carbon content, indicates a more stable molecular structure and stronger stability of organic carbon (Wu et al., 2019). The HA/FA ratio is estimated using the following equation:

$\mathrm{HA} / \mathrm{FA}=\mathrm{C}_{\mathrm{HA}} / \mathrm{C}_{\mathrm{FA}}$

where $\mathrm{C}_{\mathrm{HA}}$ denotes humic acid carbon (HA) and $\mathrm{C}_{\mathrm{FA}}$ denotes fulvic acid carbon (FA).

\section{5 | Data analysis}

All data are expressed as their mean \pm standard deviation and analyzed with one-way analysis of variance (ANOVA). The statistical significance of the differences for different treatments at different layers was determined by analysis of variance with $P<$ 0.05 (significant) and $P<0.01$ (highly significant). All data were assessed in SPSS 19.0 and Excel 2010 software, and figures were drawn with origin 8.5 software.

\section{3 | RESULTS}

\subsection{Aggregate distribution and its stability}

With decreasing aggregate particle size, the distribution of aggregates prepared by dry sieving exhibited fluctuating variations (Figure 2). In the surface layer $(0-25 \mathrm{~cm})$ of the column (Figure 2a), for all treatments, the greatest content of aggregates was in the $1-0.25 \mathrm{~mm}$ size range, accounting for $31.70-39.34 \%$, followed by $0.25-0.05 \mathrm{~mm}$, and then 2-1 mm. Compared with CK treatments, PVC, and BSM showed significant 
increases for the distribution of aggregates within the 2-1 mm, 1-0.25 mm, and 0.25-0.05 mm particle sizes, but with a decrease in the distribution of aggregates $<0.05 \mathrm{~mm}$. There were significant differences with BSM/PVC treatments for particle sizes of $2-1 \mathrm{~mm}$ and $1-0.25 \mathrm{~mm}$ as compared to that of CK treatments $(P<0.05)$. In sample layers of 25-45 $\mathrm{cm}$ and $45-65 \mathrm{~cm}$ (Figure $2 \mathrm{~b}-\mathrm{c}$ ), for all treatments, the greatest distribution was at 1-0.25 mm particle size, followed by $2-1 \mathrm{~mm}$.

From Figure 2, in the surface layer, it can be seen that the MWD of aggregates with PVC and BSM treatments is larger than CK treatments. However, no significant differences were found among all treatments. MWD for the same treatment increased gradually with increasing depth.

\section{2 | Micromorphology}

Surface morphology images of microaggregates from the different treatments are presented in Figure 3. Treatment CK contained numerous fine particles (Figure 3(a1, b1)), but with addition of PVC, aggregate size increased and the porosity among aggregates improved (Figure 3 (a2, b2)). Following BSM treatment, the residues contained larger-sized aggregates (Figure 3(a3, b3)). These results indicated that PVC and BSM treatments effectively improved porosity, the specific surface area, and morphology, which suggested that aggregate structure and its physical characteristics were improved. Figure 3 (c1-c3) shows the particle size distribution of CK, PVC, and BSM treatments, respectively. Particle size was obtained in terms of the Gauss distribution fitting (Yao et al., 2019). From the statistical histogram, the average particle sizes of CK, PVC, and BSM treatments were estimated to be $\sim 114, \sim 157$, and $\sim 188 \mathrm{~nm}$, respectively. Based on average particle size evaluation, it can be seen that BSM treatment had the maximum sized particles, which is appropriate to improve aggregate structure. This trend was observed for all treatments, and agreed with MWD variation (Figure 2).

\section{3 | X-ray energy spectrum}

Aggregate formation is related to carbon sequestration and the presence of chemical elements among particles. Element composition and relative content of residue aggregates were determined by X-ray energy spectrum (Figure 4). Following addition of PVC and BSM treatments, the relative contents of $\mathrm{C}$ and $\mathrm{O}$ were significantly improved in bauxite residue (Figure 4(a1-a3)). Compared with CK treatments, the relative contents of $\mathrm{C}$ and $\mathrm{O}$ increased from $0.79 \%$ to $3.53 \%$ and $22.49 \%$ to $33.03 \%$, 
respectively, for PVC treatments. Nevertheless, following BSM treatment, the relative contents of $\mathrm{C}$ and $\mathrm{O}$ increased from $0.79 \%$ to $13.17 \%$ and $22.49 \%$ to $34.08 \%$ as compared to $\mathrm{CK}$, respectively. Distribution of $\mathrm{C}$ and $\mathrm{O}$ following PVC/BSM treatments was more extensive compared to CK treatments (Figure 4(b1-b3 and c1-c3), revealing that PVC/BSM applications can improve the nutrient composition and enhance the fertility performance of bauxite residue.

\subsection{Organic carbon contents}

In comparison to $\mathrm{CK}$ treatments, organic carbon in the $0-25 \mathrm{~cm}$ layer increased by $39.4 \%$ and $65.53 \%$ for PVC and BSM treatments, respectively (Figure 5a). Significant differences were found with PVC/BSM treatments compared to CK treatments $(P<0.05)$. Also, in comparison with $\mathrm{CK}$, humic acid carbon and fulvic acid carbon contents significantly increased with PVC and BSM treatments. Following amendment additions, organic carbon, humic acid, and fulvic acid carbon contents were elevated in the $25-45 \mathrm{~cm}$ layer. However, in the $45-65 \mathrm{~cm}$ layer, there was no obvious influence of amendment additions on the organic carbon fraction.

\section{5 | Aggregate-associated carbon contents}

In terms of all aggregate size fractions, organic carbon, humic acid carbon, and fulvic acid carbon increased in the order, $\mathrm{CK}<\mathrm{PVC}<\mathrm{BSM}$ (Figure 6). Significant differences were observed between BSM and the other treatments $(P<0.05)$. Figure 6(a) shows that amendment additions significantly increased organic carbon for all aggregate sizes. Organic carbon in 2-1 mm aggregates was elevated 2 and 4.12 times with PVC and BSM, respectively. Significant differences were observed between PVC/BSM and CK treatments $(P<0.05)$. In aggregates of $1-0.25 \mathrm{~mm}$, organic carbon increased 1.89 (PVC) and 3.42 (BSM) times. A similar trend was observed for organic carbon in aggregates $<0.25 \mathrm{~mm}$. Humic acid carbon for all particle sizes exhibited differences following amendment additions (Figure 6(b)). With BSM treatments, aggregates between 2-1 mm contained greater humic acid carbon contents than other aggregate sizes. Following amendment additions, the increase in humic acid carbon of macroaggregates $(>0.25 \mathrm{~mm})$ was greater than that in microaggregates $(<0.25 \mathrm{~mm})$. Fulvic acid carbon within aggregates from the different treatments is presented in Figure 6(c). Fulvic acid carbon significantly increased following PVC and BSM treatments. Fulvic acid carbon in 2-1 mm aggregates increased 1.89 (PVC) and 2.92 (BSM) times, with a significant difference observed with BSM $(P<0.05)$. For $1-0.25$ 
mm aggregates, fulvic acid carbon increased 2.02 (PVC) and 2.95 (BSM) times, whilst in 0.25-0.05 mm aggregates, it increased 1.72 (PVC) and 2.52 (BSM) times. Aggregates with a particle size of $<0.05 \mathrm{~mm}$ also contained higher fulvic acid, 1.81 (PVC) and 2.48 times (BSM). After amendment additions, humic and fulvic acid carbon were mainly concentrated on large aggregates.

The HA/FA ratio with $\mathrm{BSM}$ was greatest within the $0.05-2 \mathrm{~mm}$ particle size range (Figure 6(d)). However, no significant differences were observed for $<0.05 \mathrm{~mm}$ among the three treatments. Based on these findings, it can be concluded that amendment additions are beneficial to the formation and transformation of humic and fulvic acid carbon. This may be attributed to the amendments providing an acidic environment, further promoting the accumulation of humic and fulvic acid carbon.

\section{6 | FTIR spectroscopy}

Several distinct absorption bands were observed following FTIR analysis (Figure 7). A sharp peak at $3650 \mathrm{~cm}^{-1}$ was assigned to the $-\mathrm{OH}$ stretching vibration modes of carboxyl and hydroxyl groups (Hu et al., 2014). An absorption band located at $2507 \sim 2350 \mathrm{~cm}^{-1}$ is characteristic of $\mathrm{N}-\mathrm{H}$ stretching vibrations of amino-acids (Zhu et al., 2016a). Absorption bands at 1788, 1615, 1385, and $1091 \mathrm{~cm}^{-1}$ indicate $\mathrm{C}=\mathrm{O}$ bond stretching of ketones, $\mathrm{C}-\mathrm{C}$ and $\mathrm{C}-\mathrm{O}$ stretching vibrations of aromatic compounds, $\mathrm{C}-\mathrm{H}$ bending vibrations of alkanes, and $\mathrm{C}-\mathrm{O}$ stretching vibrations of carbohydrate or polysaccharides, respectively (Esfandbod et al., 2017). The intensity of these characteristic absorption bands corresponds to the characterization of organic functional groups. Reasonable differences were observed in all treatments despite similarities in spectral shape, which suggested that the amounts of organic functional groups and organic carbon were affected by amendment additions.

\section{4 | DISCUSSION}

\section{1 | Effect of amendment on aggregate formation}

Application of amendments can significantly improve macro-aggregate formation in bauxite residue (Tian et al., 2019a). This study has demonstrated that following PVC and BSM applications, aggregates with 1-0.25, and 0.25-0.05 mm particle sizes were significantly larger than that in CK treatments (Figure 2). This agrees with previous work by Dai et al. (2019) using barren sandy soil. MWD acts as an important parameter for stability evaluation of bauxite residue aggregates, in which stronger 
aggregate stability displays higher MWD values (Zhu et al., 2016b). In this work, the MWD for PVC and BSM treatments was higher than CK (Figure 3), revealing that a combination of amendments improved aggregate stability. Yilmaz and Sönmez (2017) confirmed that organic amendments had positive aggregating effects revealed by MWD in a clay loam. Furthermore, the average particle sizes of PVC and BSM treatments were higher than CK treatments (Figure 3). Therefore, this indicates that a combination of amendments can increase aggregate stability, which may be attributed to fresh organic materials promoting microbial activity and releasing transient binding agents that may enhance macroaggregation (Six et al., 2004). Vermicomposts are peat-like materials, with a large surface area, porosity, and microbial activity, and therefore can play an important role in the production of aggregates in bauxite residue (Courtney et al., 2009; Aksakal et al., 2016). Further, BSM may create advantageous conditions for fungal growth, which plays a vital role in aggregate formation (Zhang et al., 2017). Our results suggest that organic macromolecules such as cellulose and hemicellulose, broken down into polysaccharides, proteins, and humic substances, are formed by increasing microbial activity (Peng et al., 2016). These are important organic cementing agents in bauxite residue, which is vital for the formation of larger aggregates. In addition, mycorrhiza fungi can contribute to soil structure improvement by growth of external hyphae and create a skeletal structure that holds soil particles together, such conditions being conducive to the formation of microaggregates (Tisdall, 1994; Yilmaze and Sönmez, 2017).

\section{2 | Effect of amendments on aggregate-associated carbon contents}

Organic carbon is the main cementing agent in the formation and stabilization of soil aggregates. Incorporating amendments can modify the amount of organic carbon within different particle sizes (Chai et al., 2019). In this work, PVC and BSM additions increased organic carbon in aggregates despite the difference in particle size. In particular, aggregates ranging from 1-0.25 $\mathrm{mm}$ and 0.25-0.05 mm exhibited variations, indicating that fresh exogenous carbon is mostly distributed in macroaggregates. In addition, the growth rate of organic carbon with BSM treatments was significantly higher than with PVC. This result was consistent with work reported by You et al. (2018) and Dai et al. (2019). You et al. (2018) found that organic amendments enhanced organic carbon stored in aggregates and aggregate formation during soil formation in metallic tailings. Dai et al. (2019) confirmed that organic waste additions enhanced aggregate stability and organic carbon contents in barren 
soil. This may be attributed to the rich fungal abundance and efficient microbial biomass generation resulting in carbon accumulation (Kallenbach et al., 2016). By facilitating microbial metabolism, extracellular polysaccharide production may increase, and produce a positive effect on aggregate formation (Dai et al., 2019). The decomposed products have a stronger cementing effect, further strengthening carbon sequestration (Jones et al., 2011; Peng et al., 2016).

The composition of humic substances was generally greater in aggregates from PVC and BSM treatments (Figure 4b-c). Vermicompost appears to provide carbon- and nitrogen- sources for adequate microbial nutrition, resulting in mineralization and the generation of more carbon sources and stable humus promoting steady aggregate formation (Zhang et al., 2011; Aksakal et al., 2016). The combination of amendments also increased microbial metabolism, which results in further mineralization and the generation of more carbon sources (Tian et al., 2019b; Zhang et al., 2019). Addition of mycorrhizal fungi increased microbial activity and production of carbon rich compounds (Yilmaze and Sönmez, 2017). This agrees with existing literature reported by Lugato et al (2010). Compared with CK treatments, organic fertilizer application increased the carbon content of the humic fraction in aggregates. Bongiovanni and Lobartini (2006) studied forest and arable soils, and reported that humic acid carbon in macroaggregates was greater than in microaggregates. Based on the soil aggregate hierarchy formation theory (Six et al., 2004), macroaggregates consist of microaggregates, which are bound by various organic cements. Humic substrates, acting as an essential cementing material, play an important role in aggregate formation, resulting in greater humic carbon in macroaggregates compared with microaggregates (Lugato et al., 2010; Paul, 2016).

\section{3 | Relation of aggregate-associated carbon and aggregate stability}

To elucidate the relationship between aggregate-associated carbon and aggregate stability, the influence of amendments on organic carbon was investigated. It can be observed from Table 2 that aggregate-associated carbon and MWD exhibited a highly significant positive correlation $(P<0.01)$. The different aggregate particle sizes may not only affect organic carbon properties, but also play different roles in the contribution of organic carbon to aggregate stability (Bronick and Lal, 2005). Observation indicates that organic carbon, fulvic acid carbon, and humic acid carbon in aggregates of 2-1 $\mathrm{mm}$ and $1-0.25 \mathrm{~mm}$ act as the main factors, which affect aggregate stability of bauxite residue (Table 2). There are potential mechanisms that 
might bring about an increase in aggregate stability (Figure 8). Initially, enough $\mathrm{Ca}^{2+}$, as a multivalent metallic ion, is generated via phosphogypsum supply, which connects fine clay particles and organic carbon, thereby providing effective cementation. The enhanced cementation is favorable to aggregate formation, and gradually intercepts organic carbon (Chai et al., 2019; Xue et al., 2019b). In addition, vermicompost contains numerous microorganisms, generating polysaccharides and metabolites, which can also effectively facilitate the agglomeration of bauxite residue particles (Tian et al., 2019b). Vermicompost also increases microbial activity by aeration and fermentation of amendment substrates, leading to a composition or humification effect (Aksakal et al., 2016). Finally, microorganisms may decompose organic waste to produce humic substances and polysaccharide/lignin, which can act as cementing agents to stimulate aggregate formation (Verchot et al., 2011; Yilmaze and Sönmez, 2017; Dai et el., 2019). Thus, the physical properties and the fertility performance of bauxite residue are improved.

\section{5 | CONCLUSION}

This study investigated the combined effect of amendments on aggregation and organic carbon content of bauxite residue following different treatments. Results suggested that in comparison with CK treatments, amendment additions of both PVC and BSM increased the contents of organic carbon, humic acid carbon, and fulvic acid carbon in all particle sizes, and enhanced the immobilization of carbon in bauxite residue. A positive correlation between the contents of organic carbon, humic acid carbon and fulvic acid carbon in bauxite residue and MWD of aggregates was observed, demonstrating that amendment additions contribute to the formation and stability of bauxite residue aggregates. Specifically, for macroaggregates in BSM treatments, organic carbon was much greater than that of PVC treatments, which can be attributed to organic macromolecule formation by increasing microbial activity. These findings provide a new perspective for BSM treatments as a desirable practice for accelerating soil formation of bauxite residue. 


\section{ACKNOWLEDGMENTS}

This work was supported by the National Natural Science Foundation of China (Grant No. 41701587, 41877511), the Fundamental Research Funds for the Central Universities of Central South University (No. 2019zzts240), the Open Sharing Fund for the Large-scale Instruments and Equipments of Central South University (No. CSUZC201910) and the Fundamental Research Funds for the Central Universities of Central South University (202045010).

\section{CONFLICT OF INTEREST}

The authors declare no conflict of interest

\section{ORCID}

Shengguo Xue https://orcid.org/0000-0003-2801-0238

Feng Zhu https://orcid.org/0000-0002-8468-183X 


\section{REFERENCES}

Aksakal, E. L., Sari, S., \& Angin, I. (2016). Effects of vermicompost application on soil aggregation and certain physical properties. Land Degradation \& Development, 27, 983-995. DOI: 10.1002/ldr.2350

Bongiovanni, M. D., \& Lobartini, J. C. (2006). Particulate organic matter, carbohydrate, humic acid contents in soil macro- and microaggregates as affected by cultivation. Geoderma, 136, 660-665. DOI: 10.1016/j.geoderma.2006.05.002

Bronick, C. J., \& Lal, R. (2005). Soil structure and management: a review. Geoderma, 124, 3-22. DOI: 10.1016/j.geoderma.2004.03.005

Burke, I. T., Mayes, W. M., Peacock, C. L., Brown, A. P., Jarvis, A. P., \& Gruiz, K. (2012). Speciation of arsenic, chromium, and vanadium in red mud samples from the Ajka spill site, Hungary. Environmental Science \& Technology, 46, 3085-3092

Chai, Y. J., Zeng, X. B., E, S. Z., Che, Z. X., Bai, L. Y., Su, S. M., \& Wang, Y. N. (2019). The stability mechanism for organic carbon of aggregate fractions in the irrigated desert soil based on the long-term fertilizer experiment of China. Gatena, 173, 312-320. DOI: 10.1016/j.catena.2018.10.026

Chaplot, V., \& Cooper, M. (2015). Soil aggregate stability to predict organic carbon outputs from soils. Geoderma, 243-244, 205-213. DOI: 10.1016/j.geoderma.2014.12.013

Cong, P. F., Ouyang, Z., Hou, R. X., \& Han, D. R. (2017). Effects of application of microbial fertilizer on aggregation and aggregate-associated carbon in saline soils. Soil \& Tillage Research, 168, 33-41. DOI: 10.1016/j.still.2016.12.005

Courtney, R., Harrington, T., \& Byrne, K. A. (2013). Indicators of soil formation in restored bauxite residues. Ecological Engineering, 58, 63-68. DOI: 10.1016/j.ecoleng.2013.06.022

Courtney, R. G., Jordan, S. N., \& Harrington, T. (2009). Physico-chemical changes in bauxite residue following application of spent mushroom compost and gypsum. Land Degradation \& Development, 20, 572-581. DOI: 10.1002/ldr.926

Dai, H. C., Chen, Y. Q., Liu, K. C., Li, Z. X., Qian, X., Zang, H. D., Yang, X. L., Zhao, Y. X., Shen, Y. W., Li, Z. J., \& Sui, P. (2019). Water-stable aggregates and carbon accumulation in barren sandy soil depend on organic amendment method: A three-year field study. Journal of Cleaner Production, 212, 393-400. DOI: 10.1016/J.JCLEPRO.2018.12.013

Di Carlo, E., Chen, C. R., Haynes, R. J., Phillips, I. R., \& Courtney, R. (2019). Soil quality and vegetation performance indicators for sustainable rehabilitation of bauxite residue disposal areas: a review. Soil Research, 57, 419-446. DOI: 10.1071/SR18348

Ferro, N. D., Berti, A., Francioso, O., Ferrari, E., Matthews, G. P., \& Morari, F. (2012). Investigating the effects of wettability and pore size distribution on aggregate stability: the role of soil organic matter and the humic fraction. European Journal of Soil Science, 152-164. DOI: 10.1111/j.1365-2389.2012.01427.x

Esfandbod, M., Phillips, I. R., Miller, B., Rashti, M. R., Lan, Z. M., Srivastava, P., Singh, B., \& Chen, C. R. (2017). Aged acidic biochar increases nitrogen retention and decreases ammonia volatilization in alkaline bauxite residue sand. Ecological Engineering, 98, 157-165. DOI: 10.1016/j.ecoleng. 2016.10.077

Goloran, J. B., Phillips, I. R., \& Chen, C. R. (2017). Forms of nitrogen alter plant phosphorus uptake and pathways in rehabilitated highly alkaline bauxite processing residue sand. Land Degradation \& Development, 28, 628-637. DOI: 10.1002/ldr.2630 
Higgins, D., Curtin, T., \& Courtney, R. (2017). Effectiveness of a constructed wetland for treating alkaline bauxite residue leachate: a 1-year field study. Environmental Science \& Pollution Research, 24, 8516-8524. DOI 10.1007/s11356-017-8544-1

Hu, W., Zou, L. L., Chen, X. M., Qin, N., Li, S. W., \& Bao, D.H., (2014). Highly uniform resistive switching properties of amorphous InGaZnO thin films prepared by a low temperature photochemical solution deposition method. ACS Applied Materials \& Interfaces, 6, 2012-2017. DOI: 10.1021/am500048y

Jones, B. E. H., Haynes, R. J., \& Phillips I. R. (2011). Influence of organic waste and residue mud additions on chemical, physical and microbial properties of bauxite residue sand. Environmental Science \& Pollution Research, 18,199-211. DOI: 10.1007/s11356-010-0364-5

Kallenbach, C. M., Frey, S. D., \& Grandy, A. S. (2016). Direct evidence for microbial-derived soil organic matter formation and its ecophysiological controls. Nature Communications, 7, 1-10. DOI: $10.1038 /$ ncomms 13630

Kong, X. F., Tian, T., Xue, S. G., Hartley, W., Huang, L. B., Wu, C., \& Li, C. X. (2018). Development of alkaline electrochemical characteristics demonstrates soil formation in bauxite residue undergoing natural rehabilitation. Land Degradation \& Development, 29, 58-67. DOI: $10.1002 / \mathrm{ldr} .2836$

Liang, X. Q., Liu, Z. W., Liu, J., Chen, L. L., \& Tian, G. M. (2017). Soil colloidal prelease potentials under various polyacrylamide addition levels. Land Degradation \& Development, 28, 2245-2254. DOI: $10.1002 / \mathrm{ldr} .2752$

Liu, X., Zhang, W., Wu, M., Ye, Y. Y., Wang, K. L., \& Li, D. J. (2019). Changes in soil nitrogen stocks following vegetation restoration in a typical karst catchment. Land Degradation \& Development, 30, 60-72. DOI: 10.1002/ldr.3204

Lu, R. K. (2000). Analytical methods of soil agricultural chemistry. China Agricultural Science and Technology Press. Beijing

Lugato, E., Simonetti, G., Morari, F., Nardi, S., Berti, A., \& Giardini, L. (2010). Distribution of organic and humic carbon in wet-sieved aggregates of different soils under long-term fertilization experiment. Geoderma, 157, 80-85. DOI: 10.1016/j.geoderma.2010.03.017

Paul, E. A. (2016). The nature and dynamics of soil organic matter: Plant inputs, microbial transformations, and organic matter stabilization. Soil Biology \& Biochemistry, 98, 109-126. DOI: 10.1016/j.soilbio.2016.04.001

Peng, X., Zhu, Q. H., Xie, Z. B., Darboux, F., \& Holden, N. M. (2016). The impact of manure, straw and biochar amendments on aggregation and erosion in a hillslope Ultisol. Catena, 138, 30-37. DOI: 10.1016/j.catena.2015.11.008

Rabot, E., Wiesmeier, M., Schlüter, S., \& Vogel, H. J. (2018). Soil structure as an indicator of soil functions : A review. Geoderma, 314, 122-137. DOI: 10.1016/j.geoderma.2017.11.009

Senesi, N., Plaza, C., Brunetti, G., \& Polo, A. (2007). A comparative survey of recent results on humic-like fractions in organic amendments and effects on native soil humic substances. Soil Biology \& Biochemistry, 39, 1244-1262. DOI: 10.1016/j.soilbio.2006.12.002

Six, J., Bossuyt, H., Degryze, S., \& Denef, K. (2004). A history of research on the link between (micro)aggregates, soil biota, and soil organic matter dynamics. Soil \& Tillage Research. 79, 7-31. DOI: $10.1016 /$ j.still.2004.03.008

Tian, T., Ke, W. S., Zhu, F., Wang, Q. L., Ye, Y. Z., Guo, Y., \& Xue, S. G. (2019a). Effect of substrate amendment on alkaline minerals and aggregate stability in bauxite residue. Journal of 
Central South University, 26, 393-403. DOI: 10.1007/s11771-019-4011-0

Tian, T., Zhou, J. J., Zhu, F., Ye, Y. Z, Guo, Y., Hartley, W., \& Xue, S. G. (2019b). Effect of amendments on the leaching behavior of alkaline anions and metal ions in bauxite residue. Journal of Environmental Sciences, 85, 74-81. DOI: 10.1016/j.jes.2019.05.005

Tisdall, J. M. (1994). Possible role of soil microorganisms in aggregation in soils. Plant \& Soil. 159, 115-121. DOI: 10.1007/bf00000100

Verchot, L.V., Dutaur, L., Shepherd, K. D., \& Albrecht, A. (2011). Organic matter stabilization in soil aggregates: Understanding the biogeochemical mechanisms that determine the fate of carbon inputs in soils. Geoderma, 161, 182-193. DOI: 10.1016/j.geoderma.2010.12.017

Wang, C., Tu, Q. P., Dong, D., Strong, P. J, Wang, H. L, Sun, B., \& Wu, W. X. (2014). Spectroscopic evidence for biochar amendment promoting humic acid synthesis and intensifying humification during composting. Journal of Hazardous Materials, 280, 409-416. DOI: 10.1016/j.jhazmat.2014.08.030

Wu, M., Zhang, J. W., Bao, Y. Y., Liu, M., Jiang, C. Y., Feng, Y. Z., \& Li, Z. P., (2019). Long-term fertilization decreases chemical composition variation of soil humic substance across geographic distances in subtropical China. Soil \& Tillage Research, 186, 105-111. DOI: 10.1016/J.STILL.2018.10.014

Xue, S. G. (2019a). Soil formation in bauxite residue: The most promising way to large-scale and ecological disposal. Journal of Central South University, 26, 265-267. DOI: 10.1007/s11771-019-3999-5

Xue, S. G., Li, M., Jiang, J., Millar, G. J., Li, C.X., \& Kong, X. F. (2019b). Phosphogypsum stabilization of bauxite residue: Conversion of its alkaline characteristics. Journal of Environmental Sciences, 77, 1-10. DOI: 10.1016/j.jes.2018.05.016

Yao, C. Y., Ismail, M., Hao, A. Z., Thatikonda, S. K., Huang, W. H., Qin, N., \& Bao, D. H., (2019). Annealing atmosphere effect on the resistive switching and magnetic properties of spinel $\mathrm{Co}_{3} \mathrm{O}_{4}$ thin films prepared by a sol-gel technique. RSC Advances, 9, 12615-12625. DOI: 10.1039/C9RA01121H

Yilmaz, E., \& Sönmez, M. (2017). The role of organic/bio-fertilizer amendment on aggregate stability and organic carbon content in different aggregate scales. Soil \& Tillage Research. 168, 118-124. DOI: 10.1016/j.still.2017.01.003

You, F., Dalal, R., \& Huang, L. B. (2018). Initiation of soil formation in weathered sulfidic $\mathrm{Cu}-\mathrm{Pb}-\mathrm{Zn}$ tailings under subtropical and semi-arid climatic conditions. Chemosphere, 204, 318-326. Doi.org/10.1016/j.chemosphere.2018.04.037

Yousefi, M., Hajabbasi, M., \& Shariatmadari, H., (2008). Cropping system effects on carbohydrate content and water-stable aggregates in a calcareous soil of Central Iran. Soil \& Tillage Research. 101, 57-61. DOI: 10.1016/j.still.2008.06.003

Zhang, J. J., Hu, F., Li, H. X., Gao, Q., Song, X. Y., Ke, X. K., \& Wang, L. C. (2011). Effects of earthworm activity on humus composition and humic acid characteristics of soil in a maize residue amended rice-wheat rotation agroecosystem. Applied Soil Ecology, 51, 1-8. DOI: 10.1016/j.apsoil.2011.08.004

Zhang, J. J., Wei, Y. X., Liu, J. Z., Yuan, J. C., Liang, Y., Ren, J., \& Cai, H. G. (2019). Effects of maize straw and its biochar application on organic and humic carbon in water-stable aggregates of a Mollisol in Northeast China: A five-year field experiment. Soil \& Tillage Research. 190, 1-9. DOI: $10.1016 /$ j.still.2019.02.014 
Zhang, M., Cheng, G., Feng, H., Sun, B., Zhao, Y., Chen, H., Chen, J., Dyck, M., Wang, X., Zhang, J., \& Zhang, A. (2017). Effects of straw and biochar amendments on aggregate stability, soil organic carbon, and enzyme activities in the Loess Plateau, China. Environmental Science \& Pollution Research, 24, 10108-10120. DOI: 10.1007/s11356-017-8505-8

Zhu, F., Cheng, Q. Y., Xue, S. G., Li, C. X., Hartley, W., Wu, C., \& Tian, T. (2018). Influence of natural regeneration on fractal features of residue microaggregates in bauxite residue disposal areas. Land Degradation \& Development, 29, 138-149. DOI: 10.1002/ldr.2848

Zhu, F., Li, Y. B., Xue, S. G., Hartley, W., \& Wu, H. (2016a). Effects of iron-aluminium oxides and organic carbon on aggregate stability of bauxite residues. Environmental Science \& Pollution Research, 23, 9073-9081. DOI: 0.1007/s11356-016-6172-9

Zhu, F., Liao, J. X., Xue, S. G., Hartley, W., Zou, Q., \& Wu, H. (2016b). Evaluation of aggregate microstructures following natural regeneration in bauxite residue as characterized by synchrotron-based X-ray micro-computed tomography. Science of the Total Environment, 573, 155-163. DOI: 0.1016/j.scitotenv.2016.08.108 